\title{
A New Decision-Making Method for Stock Portfolio Selection Based on Computing with Linguistic Assessment
}

\author{
Chen-Tung Chen ${ }^{1}$ and Wei-Zhan Hung ${ }^{2}$ \\ ${ }^{1}$ Department of Information Management, National United University, Miao-Li 36003, Taiwan \\ ${ }^{2}$ Graduate Institute of Management, National United University, Miao-Li 36003, Taiwan
}

Correspondence should be addressed to Chen-Tung Chen, ctchen@nuu.edu.tw

Received 30 November 2008; Revised 18 March 2009; Accepted 13 May 2009

Recommended by Lean Yu

The purpose of stock portfolio selection is how to allocate the capital to a large number of stocks in order to bring a most profitable return for investors. In most of past literatures, experts considered the portfolio of selection problem only based on past crisp or quantitative data. However, many qualitative and quantitative factors will influence the stock portfolio selection in real investment situation. It is very important for experts or decision-makers to use their experience or knowledge to predict the performance of each stock and make a stock portfolio. Because of the knowledge, experience, and background of each expert are different and vague, different types of 2-tuple linguistic variable are suitable used to express experts' opinions for the performance evaluation of each stock with respect to criteria. According to the linguistic evaluations of experts, the linguistic TOPSIS and linguistic ELECTRE methods are combined to present a new decisionmaking method for dealing with stock selection problems in this paper. Once the investment set has been determined, the risk preferences of investor are considered to calculate the investment ratio of each stock in the investment set. Finally, an example is implemented to demonstrate the practicability of the proposed method.

Copyright (c) 2009 C.-T. Chen and W.-Z. Hung. This is an open access article distributed under the Creative Commons Attribution License, which permits unrestricted use, distribution, and reproduction in any medium, provided the original work is properly cited.

\section{Introduction}

The purpose of stock portfolio selection is how to allocate the capital to a large number of stocks in order to bring a most profitable return for investors [1]. For this point of view, stock portfolio decision problem can be divided into two questions.

(1) Which stock do you choose?

(2) Which investment ratio do you allocate your capital to this stock?

There are some literatures to handle the stock portfolio decision problem. Markowitz proposed the mean-variance method for the stock portfolio decision problem in 1952 [2]. 
In his method, an expected return rate of a bond is treated as a random variable. Stochastic programming is applied to solve the problem. The basic concept of his method can be expressed as follows.

(1) When the risk of stock portfolio is constant, we should pursue to maximize the return rate of stock portfolio.

(2) When the return rate of stock portfolio is constant, we should pursue to minimize the risk of stock portfolio.

The capital asset pricing model (CAPM), Sharpe-Lintner model, Black model, and two-factor model are derived from the mean-variance method $[3,4]$. The capital asset pricing model (CAPM) was developed in 1960s. The concept of the CAPM is that the excepted return rate of the capital with risk is equal to the interest rate of the capital without risk and market risk premium [4]. The methods and theory of the financial decision making can be found in [5-7]. In 1980, Saaty proposed Analytic Hierarchy Process (AHP) to deal with the stock portfolio decision problem by evaluating the performance of each company in different level of criteria [8]. Edirisinghe and Zhang [9] selected the securities by using Data Envelopment Analysis (DEA). Huang [1] defined a new definition of risk and use genetic algorithm to cope with stock portfolio decision problem. Generally, in the portfolio selection problem the decision maker considers simultaneously conflicting objectives such as rate of return, liquidity, and risk. Multiobjective programming techniques such as goal programming (GP) and compromise programming $(\mathrm{CP})$ are used to choose the portfolio [10-12]. Considering the uncertainty of investment environment, Tiryaki transferred experts' linguistic value into triangle fuzzy number and used a new fuzzy ranking and weighting algorithm to obtain the investment ratio of each stock [4]. In fact, the stock portfolio decision problem can be described as multiple criteria decision making (MCDM) problem.

Technique for Order Preference by Similarity to Ideal Solution (TOPSIS) method is developed by Hwang and Yoon [13], which is one of the well-known MCDM methods. The basic principle of the TOPSIS method is that the chosen alternative should have the shortest distance from the positive ideal solution (PIS) and the farthest distance from the negative ideal solution (NIS). It is an effective method to determine the total ranking order of decision alternatives.

The Elimination et choice in Translating to Reality (ELECTRE) method is a highly developed multicriteria analysis model which takes into account the uncertainty and vagueness in the decision process [14]. It is based on the axiom of partial comparability and it can simplify the evaluation procedure of alternative selection. The ELECTRE method can easily compare the degree of difference among all of alternatives.

In MCDM method, experts can express their opinions by using crisp value, triangle fuzzy numbers, trapezoidal fuzzy numbers, interval numbers, and linguistic variables. Due to imprecise information and experts' subjective opinion that often appear in stock portfolio decision process, crisp values are inadequate for solving the problems. A more realistic approach may be to use linguistic assessments instead of numerical values $[15,16]$. The 2tuple linguistic representation model is based on the concept of symbolic translation $[17,18]$. Experts can apply 2-tuple linguistic variables to express their opinions and obtain the final evaluation result with appropriate linguistic variable. It is an effective method to reduce the mistakes of information translation and avoid information loss through computing with words [19]. In general, decision makers would use the different 2-tuple linguistic variables based on their knowledge or experiences to express their opinions [20]. In this paper, we use different type of 2-tuple linguistic variable to express experts' opinions and combine 


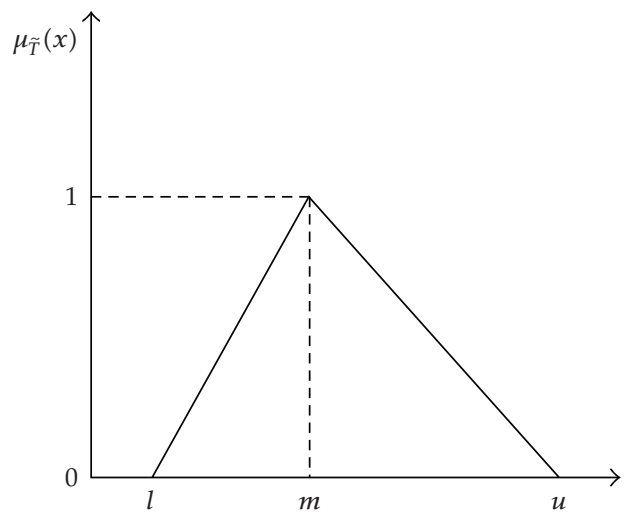

Figure 1: Triangular fuzzy number $\widetilde{T}$.

linguistic ELECTRE method with TOPSIS method to obtain the final investment ratio which is reasonable in real decision environment.

This paper is organized as follows. In Section 2, we present the context of fuzzy set and the definition and operation of 2-tuple linguistic variable. In Section 3, we describe the detail of the proposed method. In Section 4, an example is implemented to demonstrate the procedure for the proposed method. Finally, the conclusion is discussed at the end of this paper.

\section{The 2-Tuple Linguistic Representation}

\subsection{Fuzzy Set and Triangular Fuzzy Number}

Fuzzy set theory is first introduced by Zadeh in 1965 [21]. Fuzzy set theory is a very feasible method to handle the imprecise and uncertain information in a real world [22]. Especially, it is more suitable for subjective judgment and qualitative assessment in the evaluation processes of decision making than other classical evaluation methods applying crisp values [23, 24].

A positive triangular fuzzy number (PTFN) $\widetilde{T}$ can be defined as $\widetilde{T}=(l, m, u)$, where $l \leq m \leq u$ and $l>0$, shown in Figure 1. The membership function $\mu_{\widetilde{T}}(x)$ of positive triangular fuzzy number (PTFN) $\tilde{T}$ is defined as [15]

$$
\mu_{\tilde{T}}(x)= \begin{cases}\frac{x-l}{m-l}, & l<x<m, \\ \frac{u-x}{u-m}, & m<x<u, \\ 0, & \text { otherwise. }\end{cases}
$$

A linguistic variable is a variable whose values are expressed in linguistic terms. In other words, variable whose values are not numbers but words or sentences in a nature or artificial language [25-27]. For example, "weight" is a linguistic variable whose values are very low, low, medium, high, very high, and so forth. These linguistic values can also be represented by fuzzy numbers. There are two advantages for using triangular fuzzy number to express linguistic variable [28]. First, it is a rational and simple method to use triangular 
fuzzy number to express experts' opinions. Second, it is easy to do fuzzy arithmetic when using triangular fuzzy number to express the linguistic variable. It is suitable to represent the degree of subjective judgment in qualitative aspect than crisp value.

\subsection{The 2-Tuple Linguistic Variable}

Let $S=\left\{s_{0}, s_{1}, s_{2}, \ldots, s_{g}\right\}$ be a finite and totally ordered linguistic term set. The number of linguistic term is $g+1$ in set $S$. A 2-tuple linguistic variable can be expressed as $\left(s_{i}, \boldsymbol{\alpha}_{i}\right)$, where $S_{i}$ is the central value of $i$ th linguistic term in $S$ and $\alpha_{i}$ is a numerical value representing the difference between calculated linguistic term and the closest index label in the initial linguistic term set. The symbolic translation function $\Delta$ is presented in [29] to translate crisp value $\beta$ into a 2-tuple linguistic variable. Then, the symbolic translation process is applied to translate $\beta(\beta \in[0,1])$ into a 2-tuple linguistic variable. The generalized translation function can be represented as [30]:

$$
\begin{gathered}
\Delta:[0,1] \longrightarrow S \times\left[-\frac{1}{2 g}, \frac{1}{2 g}\right) \\
\Delta(\beta)=\left(s_{i}, \alpha_{i}\right),
\end{gathered}
$$

where $i=\operatorname{round}(\beta \times g), \alpha_{i}=\beta(-i / g)$ and $\alpha_{i} \in[-1 / 2 g, 1 / 2 g)$.

A reverse function $\Delta^{-1}$ is defined to return an equivalent numerical value $\beta$ from 2-tuple linguistic information $\left(s_{i}, \alpha_{i}\right)$. According to the symbolic translation, an equivalent numerical value $\beta$ is obtained as follow [30]

$$
\Delta^{-1}\left(s_{i}, \alpha_{i}\right)=\frac{i}{g}+\alpha_{i}=\beta
$$

Let $x=\left\{\left(r_{1}, \alpha_{1}\right), \ldots,\left(r_{n}, \alpha_{n}\right)\right\}$ be a 2-tuple linguistic variable set. The arithmetic mean $\bar{X}$ is computed as [31]

$$
\bar{X}=\Delta\left(\frac{1}{n} \sum_{i=1}^{n} \Delta^{-1}\left(r_{i}, \alpha_{i}\right)\right)=\left(s_{m}, \alpha_{m}\right),
$$

where $n$ is the amount of 2-tuple linguistic variable. The $\left(s_{m}, \alpha_{m}\right)$ is a 2-tuple linguistic variable which is represented as the arithmetic mean.

In general, decision makers would use the different 2-tuple linguistic variables based on their knowledge or experiences to express their opinions [20]. For example, the different types of linguistic variables show as Table 1. Each 2-tuple linguistic variable can be represented as a triangle fuzzy number. A transformation function is needed to transfer these 2-tuple linguistic variables from different linguistic sets to a standard linguistic set at unique domain. In the method of Herrera and Martinez [29], the domain of the linguistic variables will increase as the number of linguistic variable is increased. To overcome this drawback, a new translation function is applied to transfer a crisp number or 2-tuple linguistic variable to a standard linguistic term at the unique domain [30]. Suppose that the interval $[0,1]$ is the unique domain. The linguistic variable sets with different semantics (or types) will be 
defined by partitioning the interval $[0,1]$. Transforming a crisp number $\beta(\beta \in[0,1])$ into ith linguistic term $\left(s_{i}^{n(t)}, \alpha_{i}^{n(t)}\right)$ of type $t$ as

$$
\Delta_{t}(\beta)=\left(s_{i}^{n(t)}, \alpha_{i}^{n(t)}\right)
$$

where $i=\operatorname{round}\left(\beta \times g_{t}\right), \alpha_{i}^{n(t)}=\beta\left(-i / g_{t}\right), g_{t}=n(t)-1$, and $n(t)$ is the number of linguistic variable of type $t$.

Transforming $i$ th linguistic term of type $t$ into a crisp number $\beta(\beta \in[0,1])$ as

$$
\Delta_{t}^{-1}\left(s_{i}^{n(t)}, \alpha_{i}^{n(t)}\right)=\frac{i}{g_{t}}+\alpha_{i}^{n(t)}=\beta
$$

where $g_{t}=n(t)-1$ and $\alpha_{i}^{n(t)} \in\left[-1 / 2 g_{t}, 1 / 2 g_{t}\right)$.

Therefore, the transformation from $i$ th linguistic term $\left(s_{i}^{n(t)}, \alpha_{i}^{n(t)}\right)$ of type $t$ to $k$ th linguistic term $\left(s_{k}^{n(t+1)}, \alpha_{k}^{n(t+1)}\right)$ of type $t+1$ at interval $[0,1]$ can be expressed as

$$
\Delta_{t+1}\left(\Delta_{t}^{-1}\left(s_{i}^{n(t)}, \alpha_{i}^{n(t)}\right)\right)=\left(s_{k}^{n(t+1)}, \alpha_{k}^{n(t+1)}\right)
$$

where $g_{t+1}=n(t+1)-1$ and $\alpha_{k}^{n(t+1)} \in\left[-1 / 2 g_{t+1}, 1 / 2 g_{t+1}\right)$.

\section{Proposed Method}

Because of the knowledge, experience and background of each expert is different and experts' opinions are usually uncertain and imprecise, it is difficult to use crisp value to express experts' opinions in the process of evaluating the performance of stock. Instead of crisp value, the 2-Tuple linguistic valuable which is an effective method to reduce the mistakes of information translation and avoid information loss through computing with words to express experts' opinions [19]. In this paper, different types of 2-tuple linguistic variables are used to express experts' opinions.

The TOPSIS method is one of the well-known MCDM methods. It is an effective method to determine the ranking order of decision alternatives. However, this method cannot distinguish the difference degree between two decision alternatives easily. Based on the axiom of partial comparability, the ELECTRE method can easily compare the degree of difference among of all alternatives. This method always cannot provide the total ordering of all decision alternatives. Therefore, the ELECTRE and TOPSIS methods are combined to determine the final investment ratio.

In the proposed model, the subjective opinions of experts can be expressed by different 2-tuple linguistic variables in accordance with their habitual knowledge and experience. After aggregating opinions of all experts, the linguistic TOPSIS and linguistic ELECTRE methods are applied to obtain the investment portfolio sets $\Omega_{t}$ and $\Omega_{e}$, respectively. The strict stock portfolio set $\Omega_{i p}$ is determined by intersection $\Omega_{t}$ with $\Omega_{e}$. In general, the risk preference of investor can be divided into three types such as risk-averter, risk-neutral, and risk-loving. Considering the risk preference of investor, we can calculate the investment ratio of each 


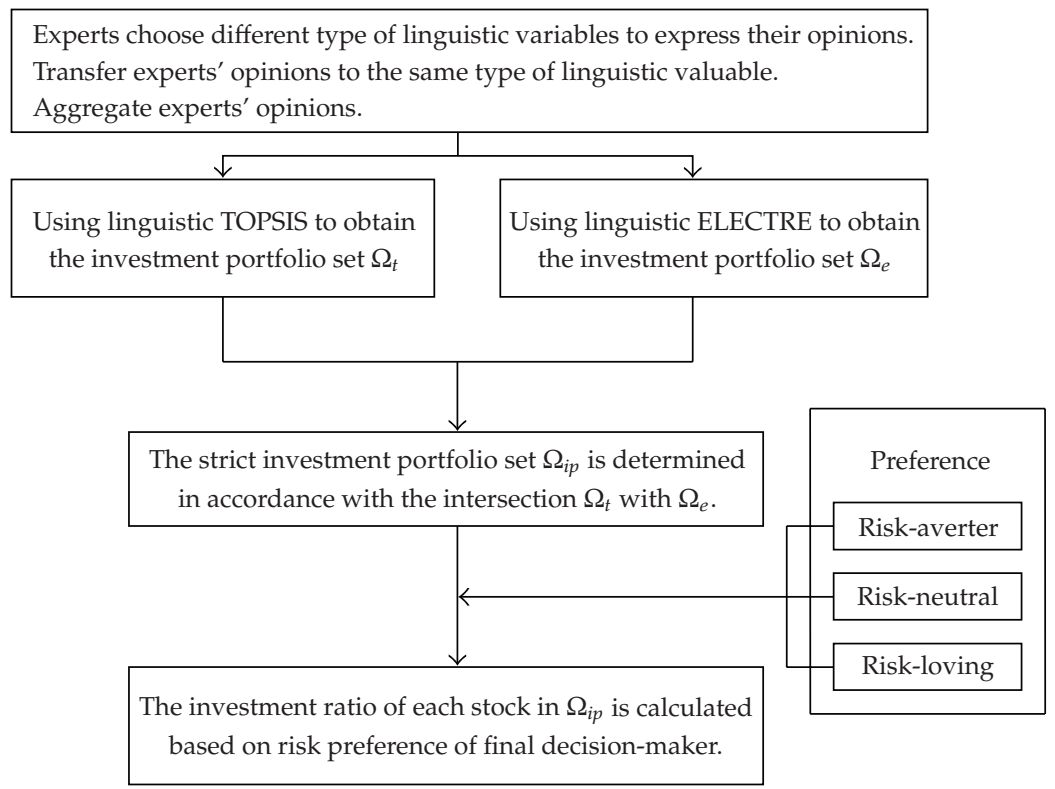

Figure 2: The decision-making process of the proposed method.

stock in strict stock portfolio set $\Omega_{i p}$. The decision process of the proposed method is shown as in Figure 2.

In general, a stock portfolio decision may be described by means of the following sets:

(i) a set of experts or decision-makers called $E=\left\{E_{1}, E_{2}, \ldots, E_{K}\right\}$;

(ii) a set of stocks called $S=\left\{S_{1}, S_{2}, \ldots, S_{m}\right\}$;

(iii) a set of criteria $C=\left\{C_{1}, C_{2}, \ldots, C_{n}\right\}$ with which stock performances are measured;

(iv) a weight vector of each criterion $W=\left(W_{1}, W_{2}, \ldots, W_{n}\right)$;

(v) a set of performance ratings of each stock with respect to each criterion called $\widetilde{S}_{i j}, i=1,2, \ldots, m, j=1,2, \ldots, n$.

According to the aforementioned description, there are $K$ experts, $\mathrm{m}$ stocks and $n$ criteria in the decision process of stock portfolio. Experts can express their opinions by different 2-tuple linguistic variables. The $k$ th expert's opinion about the performance rating of $i$ th stock with respect to $j$ th criterion can be represented as $\widetilde{S}_{i j}^{k}=\left(S_{i j}^{k}, \alpha_{i j}^{k}\right)$. The $k$ th expert's opinion about the importance of $j$ th criterion can be represented as $\widetilde{W}_{j k}=\left(S_{j k}^{w}, \alpha_{j k}^{w}\right)$.

The aggregated linguistic rating $\widetilde{S}_{i j}$ of each stock with respect to each criterion can be calculated as

$$
\tilde{S}_{i j}=\Delta\left(\frac{1}{K} \sum_{k=1}^{K} \Delta^{-1}\left(S_{i j}^{k}, \alpha_{i j}^{k}\right)\right)=\left(S_{i j}, \alpha_{i j}\right)
$$


The aggregated linguistic weight $\tilde{w}_{j}$ of each criterion can be calculated as

$$
\widetilde{W}_{j}=\Delta\left(\frac{1}{K} \sum_{k=1}^{K} \Delta^{-1}\left(S_{j k}^{w}, \alpha_{j k}^{w}\right)\right)=\left(S_{j}^{w}, \alpha_{j}^{w}\right) .
$$

\subsection{Linguistic TOPSIS Method}

Considering the different importance of each criterion, the weighted linguistic decision matrix is constructed as

$$
\tilde{V}\left[\tilde{v}_{i j}\right]_{m \times n^{\prime}} \quad i=1,2, \ldots, m, j=1,2, \ldots, n,
$$

where $\tilde{v}_{i j}=\tilde{x}_{i j}(\cdot) \tilde{w}_{j}=\Delta\left(\Delta^{-1}\left(S_{i j}, \alpha_{i j}\right) * \Delta^{-1}\left(S_{j}^{w}, \alpha_{j}^{w}\right)\right)=\left(S_{i j}^{v}, \alpha_{i j}^{v}\right)$.

According to the weighted linguistic decision matrix, the linguistic positive-ideal solution (LPIS, $S^{*}$ ) and linguistic negative-ideal solution (LNIS, $S^{-}$) can be defined as

$$
\begin{aligned}
& S^{*}=\left(\widetilde{v}_{1}^{*}, \widetilde{v}_{2}^{*}, \ldots, \widetilde{v}_{n}^{*}\right), \\
& S^{-}=\left(\widetilde{v}_{1}^{-}, \widetilde{v}_{2}^{-}, \ldots, \widetilde{v}_{n}^{-}\right),
\end{aligned}
$$

where $\widetilde{v}_{j}^{*}=\max _{i}\left\{\left(S_{i j}^{v}, \alpha_{i j}^{v}\right)\right\}$ and $\widetilde{v}_{j}^{-}=\min _{i}\left\{\left(S_{i j}^{v}, \alpha_{i j}^{v}\right)\right\}, i=1,2, \ldots, m, j=1,2, \ldots, n$.

The distance of each stock $S_{i}(i=1,2, \ldots, m)$ from $S^{*}$ and $S^{-}$can be currently calculated as

$$
\begin{aligned}
& d_{i}^{*}=d\left(S_{i}, S^{*}\right)=\sqrt{\sum_{j=1}^{n} d\left(\widetilde{v}_{i j}, \tilde{v}_{j}\right)}=\sqrt{\sum_{j=1}^{n}\left(\Delta^{-1}\left(\max _{i}\left\{\left(S_{i j}^{v}, \alpha_{i j}^{v}\right)\right\}\right)-\Delta^{-1}\left(S_{i j}^{v}, \alpha_{i j}^{v}\right)\right)^{2}}, \\
& d_{i}^{-}=d\left(S_{i}, S^{-}\right)=\sqrt{\sum_{j=1}^{n} d\left(\tilde{v}_{i j}, \tilde{v}_{j}\right)}=\sqrt{\sum_{j=1}^{n}\left(\Delta^{-1}\left(S_{i j}^{v}, \alpha_{i j}^{v}\right)-\Delta^{-1}\left(\min _{i}\left\{\left(S_{i j}^{v}, \alpha_{i j}^{v}\right)\right\}\right)\right)^{2}} .
\end{aligned}
$$

A closeness coefficient is defined to determine the ranking order of all stocks once $d_{i}^{*}$ and $d_{i}^{-}$of each stock $S_{i}(i=1,2, \ldots, m)$ have been calculated. The closeness coefficient represents the distances to the linguistic positive-ideal solution $\left(S^{*}\right)$ and the linguistic negative-ideal solution $\left(S^{-}\right)$simultaneously by taking the relative closeness to the linguistic positive-ideal solution. The closeness coefficient $\left(\mathrm{CC}_{i}\right)$ of each stock is calculated as

$$
\mathrm{CC}_{i}=\frac{d_{i}^{-}}{d_{i}^{*}+d_{i}^{-}}, \quad i=1,2, \ldots, m
$$

The higher $\mathrm{CC}_{i}$ means that stock $S_{i}$ relatively close to positive ideal solution, the stock $S_{i}$ has more ability to compete with each others. If the closeness coefficient of stock $S_{i}$ is greater than the predetermined threshold value $\beta_{t}$, we consider stock $S_{i}$ is good enough to choose in the investment portfolio set. According to closeness coefficient of each stock, the 
investment portfolio set $\Omega_{t}$ can be determined based on investment threshold value $\beta_{t}$ as $\Omega_{t}=\left\{S_{i} \mid C C_{i} \geq \beta_{t}\right\}$. Finally, the investment ratio of each stock in $\Omega_{t}$ can be calculated as

$$
P_{t}\left(S_{i}\right)= \begin{cases}\frac{\mathrm{CC}\left(S_{i}\right)}{\sum_{S_{i} \in \Omega_{t}} \mathrm{CC}\left(S_{i}\right)}, & S_{i} \in \Omega_{t}, \\ 0, & S_{i} \notin \Omega_{t},\end{cases}
$$

where $P_{t}\left(S_{i}\right)$ is the investment ratio of each stock by linguistic TOPSIS method.

\subsection{Linguistic ELECTRE Method}

According to the ELECTRE method, the concordance index $C_{j}\left(S_{i}, S_{l}\right)$ is calculated for $S_{i}$ and $S_{l}(i \neq l, i, l=1,2, \ldots, m)$ with respect to each criterion as

$$
C_{j}\left(S_{i}, S_{l}\right)= \begin{cases}1, & \Delta^{-1}\left(\widetilde{s}_{i j}\right) \geq \Delta^{-1}\left(\widetilde{s}_{l j}\right)-q_{j}, \\ \frac{\Delta^{-1}\left(\widetilde{s}_{i j}\right)-\Delta^{-1}\left(\widetilde{s}_{l j}\right)+p_{j}}{p_{j}-q_{j}}, & \Delta^{-1}\left(\widetilde{s}_{l j}\right)-q_{j} \geq \Delta^{-1}\left(\widetilde{s}_{i j}\right) \geq \Delta^{-1}\left(\widetilde{s}_{l j}\right)-p_{j}, \\ 0, & \Delta^{-1}\left(\widetilde{s}_{i j}\right) \leq \Delta^{-1}\left(\widetilde{s}_{l j}\right)-p_{j},\end{cases}
$$

where $q_{j}$ and $p_{j}$ are indifference and preference threshold values for criterion $C_{j}, p_{j}>q_{j}$.

The discordance index $D_{j}\left(S_{i}, S_{l}\right)$ is calculated for each pair of stocks with respect to each criterion as

$$
D_{j}\left(S_{i}, S_{l}\right)= \begin{cases}1, & \Delta^{-1}\left(\widetilde{s}_{i j}\right) \leq \Delta^{-1}\left(\widetilde{s}_{l j}\right)-v_{j}, \\ \frac{\Delta^{-1}\left(\widetilde{s}_{l j}\right)-p_{j}-\Delta^{-1}\left(\widetilde{s}_{i j}\right)}{v_{j}-p_{j}}, & \Delta^{-1}\left(\widetilde{s}_{l j}\right)-p_{j} \geq \Delta^{-1}\left(\widetilde{s}_{i j}\right) \geq \Delta^{-1}\left(\widetilde{s}_{l j}\right)-v_{j}, \\ 0, & \Delta^{-1}\left(\widetilde{s}_{i j}\right) \geq \Delta^{-1}\left(\widetilde{s}_{l j}\right)-p_{j},\end{cases}
$$

where $v_{j}$ is the veto threshold for criterion $C_{j}, v_{j}>p_{j}$.

Calculate the overall concordance index $C\left(S_{i}, S_{l}\right)$ as

$$
C\left(S_{i}, S_{l}\right)=\sum_{j=1}^{n} \Delta^{-1}\left(\widetilde{w}_{j}\right) * C_{j}\left(S_{i}, S_{l}\right) .
$$

The credibility matrix $S\left(S_{i}, S_{l}\right)$ of each pair of the stocks is calculated as

$$
S\left(S_{i}, S_{l}\right)= \begin{cases}C\left(S_{i}, S_{l}\right), & \text { if } D_{j}\left(S_{i}, S_{l}\right) \leq C\left(S_{i}, S_{l}\right) \forall j, \\ C\left(S_{i}, S_{l}\right) \prod_{j \in J\left(S_{i}, S_{l}\right)} \frac{1-D_{j}\left(S_{i}, S_{l}\right)}{1-C\left(S_{i}, S_{l}\right)}, & \text { otherwise, }\end{cases}
$$

where $J\left(S_{i}, S_{l}\right)$ is the set of criteria for which $D_{j}\left(S_{i}, S_{l}\right)>C\left(S_{i}, S_{l}\right), i \neq l, i, l=1,2, \ldots, m$. 
The concordance credibility and discordance credibility degrees are defined as [32]

$$
\begin{aligned}
\phi^{+}\left(S_{i}\right) & =\sum_{i \neq l} S\left(S_{i}, S_{l}\right), \\
\phi^{-}\left(S_{i}\right) & =\sum_{i \neq l} S\left(S_{l}, S_{i}\right) .
\end{aligned}
$$

The concordance credibility degree represents that the degree of stock $S_{i}$ is at least as good as all the other stocks. The discordance credibility degree represents that the degree of all the other stocks is at least as good as stock $S_{i}$.

Then, the net credibility degree is defined as $\phi\left(S_{i}\right)=\phi^{+}\left(S_{i}\right)-\phi^{-}\left(S_{i}\right)$. If the net credibility degree of stock $S_{i}$ is higher, then it represents a higher attractiveness of stock $S_{i}$. In order to determine the investment ratio, the outranking index of stock $S_{i}$ can be defined as

$$
\operatorname{OTI}\left(S_{i}\right)=\frac{\phi\left(S_{i}\right) /(m-1)+1}{2}
$$

Property 3.1. According to the definition of $\operatorname{OTI}\left(S_{i}\right)$, we can find $0 \leq \mathrm{OTI}\left(S_{i}\right) \leq 1$.

Proof. Because $\phi\left(S_{i}\right)=\phi^{+}\left(S_{i}\right)-\phi^{-}\left(S_{i}\right)=\sum_{i \neq l} S\left(S_{i}, S_{l}\right)-\sum_{i \neq l}\left(S_{l} \cdot S_{i}\right), i \neq l, i, l=1,2, \ldots, m$.

If the stock $S_{i}$ is better than $S_{l}$ with respect to each criterion, the best case is

$$
\sum_{i \neq l} S\left(S_{i}, S_{l}\right)-\sum_{i \neq l}\left(S_{l}, S_{i}\right)=m-1
$$

If the stock $S_{i}$ is worse than $S_{l}$ with respect to each criterion, the worst case is

$$
\sum_{i \neq l} S\left(S_{i}, S_{l}\right)-\sum_{i \neq l}\left(S_{l}, S_{i}\right)=-(m-1) .
$$

Therefore, $-(m-1) \leq \phi\left(S_{i}\right) \leq m-1$.

Then, $-1 \leq \phi\left(S_{i}\right) /(m-1) \leq 1$. Finally, we can prove $0 \leq\left(\phi\left(S_{i}\right) /(m-1)+1\right) / 2=$ $\operatorname{OTI}\left(S_{i}\right) \leq 1$.

The OTI $\left(S_{i}\right)$ denotes the standardization result of the net credibility degree. According to the definition, it is easy to understand and transform the net credibility degree into interval $[0,1]$.

If the outranking index of stock $S_{i}$ is greater than the predetermined threshold value $\beta_{e}$, we consider stock $S_{i}$ is good enough to choose in the investment portfolio set. According to the outranking index of each stock, the investment portfolio set $\Omega_{e}$ can be determined based on investment threshold value $\beta_{e}$ as $\Omega_{e}=\left\{S_{i} \mid \operatorname{OTI}\left(S_{i}\right) \geq \beta_{e}\right\}$. Finally, the investment ratio of each stock in $\Omega_{e}$ can be calculated as

$$
P_{e}\left(S_{i}\right)= \begin{cases}\frac{\mathrm{OTI}\left(S_{i}\right)}{\sum_{S_{i} \in \Omega_{e}} \mathrm{OTI}\left(S_{i}\right)}, & S_{i} \in \Omega_{e}, \\ 0, & S_{i} \notin \Omega_{e},\end{cases}
$$

where $P_{e}\left(S_{i}\right)$ is the investment ratio of each stock by using linguistic ELECTRE method. 


\subsection{Stock Portfolio Decision}

We can consider Linguistic TOPSIS and Linguistic ELECTRE methods as two financial experts to provide investment ratio of each stock, respectively. Smart investor will make a stock portfolio decision by considering the suggestions of investment ratio of each stock simultaneously. Therefore, the portfolio set $\Omega_{i p}$ is defined as strict stock portfolio set $\Omega_{i p}=$ $\Omega_{t} \cap \Omega_{e}$.

According to the closeness coefficient, the investment ratio of each stock in strict stock portfolio set $\Omega_{i p}$ can be calculated as

$$
P_{t_{-i p}}\left(S_{i}\right)= \begin{cases}\frac{\mathrm{CC}\left(S_{i}\right)}{\sum_{S_{i} \in \Omega_{i p}} \operatorname{CC}\left(S_{i}\right)}, & S_{i} \in \Omega_{i p}, \\ 0, & S_{i} \notin \Omega_{i p} .\end{cases}
$$

According to the outranking index, the investment ratio of each stock in strict stock portfolio set $\Omega_{i p}$ can be calculated as

$$
P_{e \_i p}\left(S_{i}\right)= \begin{cases}\frac{\mathrm{OTI}\left(S_{i}\right)}{\sum_{S_{i} \in \Omega_{i p}} \mathrm{OTI}\left(S_{i}\right)}, & S_{i} \in \Omega_{i p}, \\ 0, & S_{i} \notin \Omega_{i p} .\end{cases}
$$

In general, the investment preference of investors can be divided into three types such as risk-averter (RA), risk-neutral (RN), and risk-loving (RL). If a person is risk-averter, he/she will consider the smaller investment rates between $P_{t_{i} i p}\left(S_{i}\right)$ and $P_{e_{-} i p}\left(S_{i}\right)$. Therefore, the final ratio of each stock in strict portfolio set can be calculated as

$$
P_{\mathrm{RA}}\left(S_{i}\right)=\frac{\min \left(P_{t-i p}\left(S_{i}\right), P_{e_{-i p}}\left(S_{i}\right)\right)}{\sum_{S_{i} \in \Omega_{i p}} \min \left(P_{t-i p}\left(S_{i}\right), P_{e_{-i p}}\left(S_{i}\right)\right)}
$$

If a person is risk-neutral, he/she will consider the average investment rates between $P_{t-i p}\left(S_{i}\right)$ and $P_{e_{-} i p}\left(S_{i}\right)$. Therefore, the final ratio of each stock in strict portfolio set can be calculated as

$$
P_{\mathrm{RN}}\left(S_{i}\right)=\frac{\left(P_{t i p}\left(S_{i}\right)+P_{e_{-i p}}\left(S_{i}\right)\right) / 2}{\sum_{S_{i} \in \Omega_{i p}}\left(\left(P_{t \_i p}\left(S_{i}\right)+P_{\text {eip }}\left(S_{i}\right)\right) / 2\right)} .
$$

If a person is risk-loving, he/she will consider the bigger investment rates between $P_{t i p}\left(S_{i}\right)$ and $P_{e_{-i p}}\left(S_{i}\right)$. Therefore, the final ratio of each stock in portfolio set can be calculated as

$$
P_{\mathrm{RL}}\left(S_{i}\right)=\frac{\max \left(P_{t_{-i p}}\left(S_{i}\right), P_{e_{-i p}}\left(S_{i}\right)\right)}{\sum_{S_{i} \in \Omega_{i p}} \max \left(P_{t_{-i p}}\left(S_{i}\right), P_{e_{-i p}}\left(S_{i}\right)\right)} .
$$


Table 1: Ten stocks of semiconduct industry in Taiwan.

\begin{tabular}{|c|c|c|c|}
\hline$S_{1}$ & $\begin{array}{l}\text { Taiwan Semiconductor Manufacturing Co. } \\
\text { Ltd. }\end{array}$ & $S_{2}$ & United Microelectronics Corp. \\
\hline$S_{3}$ & Advanced Semiconductor Engineering, Inc. & $S_{4}$ & Via Technologies, Inc. \\
\hline$S_{5}$ & MediaTek Inc. & $S_{6}$ & King Yuan Electronics Co. Ltd. \\
\hline$S_{7}$ & Taiwan Mask Corp. & $S_{8}$ & Winbond Electronics Corp. \\
\hline$S_{9}$ & SunPlus Technology Co. Ltd. & $S_{10}$ & Nanya Technology Corporation \\
\hline
\end{tabular}

\section{Numerical Example}

An example with ten stocks of semiconduct industry in placecountry-region, Taiwan, will be considered to determine the investment ratio of each stock in this paper. Ten stocks are shown as Table 1. A committee of three financial experts $E=\left\{E_{1}, E_{2}, E_{3}\right\}$ has been formed to evaluate the performance of each stock. They are famous professors of a department of finance at well-known university in country-regionplace, Taiwan. Their knowledge and experiences are enough to evaluate the stock performance of each company for this example. In the process of criteria selection, they considered the quantitative and qualitative factors to deal with the portfolio selection. After the serious discussion and selection by three financial experts, six criteria are considered to determined the investment ratio of each stock such as profitability $\left(C_{1}\right)$, asset utilization $\left(C_{2}\right)$, liquidity $\left(C_{3}\right)$, leverage $\left(C_{4}\right)$, valuation $\left(C_{5}\right)$, growth $\left(C_{6}\right)$.

\section{Profitability $\left(C_{1}\right)$}

The goal of enterprise is tomakeaprofit. There are some indexes to evaluate the profitability of a company such as earnings per share (EPS), net profit margin, return on assets (ROA), and return on equity (ROE). The profitability of a company will influence the performance of each stock.

\section{Asset Utilization $\left(C_{2}\right)$}

Asset utilization means the efficiency of using company's resource in a period. A good company will promote the resource using efficiency as more as possible. Experts evaluate the asset utilization of the company based on receivables turnover, inventory turnover, and asset turnover.

\section{Liquidity $\left(C_{3}\right)$}

Liquidity will focus on cash flow generation and a company's ability to meet its financial obligations. When company's transfer assets ( 1 and, factory buildings, equipment, patent, goodwill) to currency in a short period, there will have some loss because the company's manager do not have enough time to find out the buyer who provide the highest price. An appropriate liquidity ratio (debt to equity ratio, current ratio, quick ratio) will both prevent liquidity risk and minimize the working capital. 


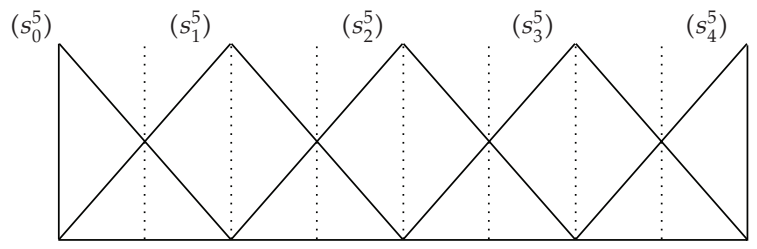

Figure 3: Membership functions of linguistic variables at type $1(t=1)$.

Table 2: Different types of linguistic variables.

\begin{tabular}{|c|c|c|c|}
\hline Type & & Linguistic variable & Figure \\
\hline \multirow[t]{2}{*}{1} & Performance & $\begin{array}{l}\text { Extremely Poor }\left(s_{0}^{5}\right) \text {, Poor }\left(s_{1}^{5}\right) \text {, Fair }\left(s_{2}^{5}\right) \text {, Good }\left(s_{3}^{5}\right) \text {, Extremely } \\
\text { Good }\left(s_{4}^{5}\right)\end{array}$ & \multirow[t]{2}{*}{ Figure 3} \\
\hline & Weight & $\begin{array}{l}\text { Extremely Low }\left(s_{0}^{5}\right) \text {, Low }\left(s_{1}^{5}\right) \text {, Fair }\left(s_{2}^{5}\right), \text { High }\left(s_{3}^{5}\right) \text {, Extremely } \\
\text { High }\left(s_{4}^{5}\right)\end{array}$ & \\
\hline \multirow[t]{2}{*}{2} & Performance & $\begin{array}{l}\text { Extremely Poor }\left(s_{0}^{7}\right) \text {, Poor }\left(s_{1}^{7}\right) \text {, Medium Poor }\left(s_{2}^{7}\right) \text {, Fair }\left(s_{3}^{7}\right) \text {, } \\
\text { Medium Good }\left(s_{4}^{7}\right) \text {, Good }\left(s_{5}^{7}\right) \text {, Extremely Good }\left(s_{6}^{7}\right)\end{array}$ & \multirow[t]{2}{*}{ Figure 4} \\
\hline & Weight & $\begin{array}{l}\text { Extremely Low }\left(s_{0}^{7}\right), \text { Low }\left(s_{1}^{7}\right) \text {, Medium Low }\left(s_{2}^{7}\right) \text {, Fair }\left(s_{3}^{7}\right) \text {, } \\
\text { Medium High }\left(s_{4}^{7}\right), \operatorname{High}\left(s_{5}^{7}\right), \text { Extremely High }\left(s_{6}^{7}\right)\end{array}$ & \\
\hline \multirow[t]{2}{*}{3} & Performance & $\begin{array}{l}\text { Extremely Poor }\left(s_{0}^{9}\right) \text {, Very Poor }\left(s_{1}^{9}\right) \text {, Poor }\left(s_{2}^{9}\right) \text {, Medium Poor } \\
\left(s_{3}^{9}\right) \text {, Fair }\left(s_{4}^{9}\right) \text {, Medium Good }\left(s_{5}^{9}\right), \text { Good }\left(s_{6}^{9}\right) \text {, Very Good }\left(s_{7}^{9}\right) \text {, } \\
\text { Extremely Good }\left(s_{8}^{9}\right)\end{array}$ & \multirow[t]{2}{*}{ Figure 5} \\
\hline & Weight & $\begin{array}{l}\text { Extremely Low }\left(s_{0}^{9}\right) \text {, Very Low }\left(s_{1}^{9}\right) \text {, Low }\left(s_{2}^{9}\right) \text {, Medium Low }\left(s_{3}^{9}\right) \text {, } \\
\text { Fair }\left(s_{4}^{9}\right) \text {, Medium High }\left(s_{5}^{9}\right), \operatorname{High}\left(s_{6}^{9}\right) \text {, Very High }\left(s_{7}^{9}\right), \\
\text { Extremely High }\left(s_{8}^{9}\right)\end{array}$ & \\
\hline
\end{tabular}

\section{Leverage $\left(C_{4}\right)$}

When the return on assets is greater than lending rate, it is time for a company to lend money to operate. But increasing the company's debt will increase risk if the company does not earn enough money to pay the debt in the future. A suitable leverage ratio is one of the criteria to evaluate the performance of each stock.

\section{Valuation $\left(C_{5}\right)$}

Book value means the currency which all of the company's assets transfer to, stock value means the price if you want to buy now, earnings before amortization, interest and taxes ratio (EBAIT) means the company earns in this year, expert must consider the best time point to buy the stock by Technical Analysis (TA) and Time Series Analysis (TSA). So, valuation is also one of the criteria to evaluate the performance of each stock.

\section{Growth $\left(C_{6}\right)$}

If the scale of a company was expanded year by year, EBAIT will increase which is like "compound interest." Because of economies of scale, the growth of the company will promote asset utilization and then raise the EBAIT and EPS.

According to the proposed method, the computational procedures of the problem are summarized as follows. 


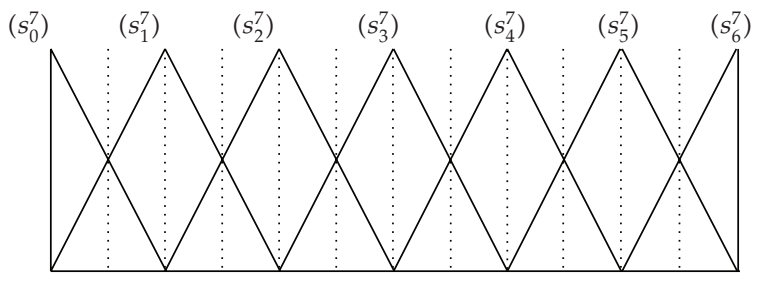

Figure 4: Membership functions of linguistic variables at type $2(t=2)$.

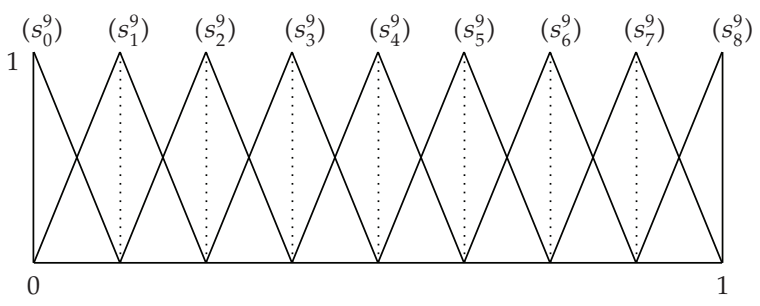

Figure 5: Membership functions of linguistic variables at type $3(t=3)$.

Table 3: Evaluation decisions (the ratings of the all stocks under all criteria) by three experts.

\begin{tabular}{ccccccccccccccccccc}
\hline & & $C_{1}$ & & & $C_{2}$ & \multicolumn{1}{c}{$C_{3}$} & & & $C_{4}$ & & & $C_{5}$ & & & $C_{6}$ \\
& $E_{1}$ & $E_{2}$ & $E_{3}$ & $E_{1}$ & $E_{2}$ & $E_{3}$ & $E_{1}$ & $E_{2}$ & $E_{3}$ & $E_{1}$ & $E_{2}$ & $E_{3}$ & $E_{1}$ & $E_{2}$ & $E_{3}$ & $E_{1}$ & $E_{2}$ & $E_{3}$ \\
\hline$S_{1}$ & F & F & G & EG & MG & VG & G & MG & VG & P & F & EG & F & G & VG & P & MG & VG \\
$S_{2}$ & P & F & MG & F & MG & G & F & F & G & EP & F & MG & P & MG & VG & P & MG & G \\
$S_{3}$ & F & F & G & G & F & MG & F & MG & G & F & F & MG & P & MG & G & F & MG & MG \\
$S_{4}$ & F & G & MG & G & G & G & F & MG & MG & F & G & G & F & MG & MG & P & EG & MG \\
$S_{5}$ & F & MG & EG & G & MG & VG & F & G & G & G & MG & VG & G & MG & VG & P & G & G \\
$S_{6}$ & P & F & G & G & F & VG & F & F & VG & P & MG & VG & F & F & G & F & F & G \\
$S_{7}$ & G & F & G & P & MG & VG & F & F & G & F & F & VG & P & MG & VG & F & MG & VG \\
$S_{8}$ & EP & MG & G & F & F & VG & EP & F & VG & EP & MG & EG & EP & MG & VG & P & MG & VG \\
$S_{9}$ & G & MG & VG & F & MG & G & F & F & VG & F & MG & VG & F & MG & VG & F & G & G \\
$S_{10}$ & EP & G & G & F & G & G & F & MG & MG & EP & MG & G & EP & F & MG & EP & MG & MG \\
\hline
\end{tabular}

Step 1. Each expert selects the suitable 2-tuple linguistic variables to express their opinions. Expert 1 uses linguistic variables with 5 scale of linguistic term set to express his opinion, expert 2 uses linguistic variables with 7 scale of linguistic term set and expert 3 uses linguistic variables with 9 scale of linguistic term set, respectively (see Table 2).

Step 2. Each expert expresses his opinion about the performance of each stock with respect to each criterion as shown in Table 3.

Step 3. Each expert expresses his opinion about the importance of each criterion as shown in Table 4 .

Step 4. Transform the linguistic ratings into the linguistic variables of type 2 and aggregate the linguistic ratings of each stock with respect to criteria as Table 5. 
Table 4: Evaluation decisions (the weightings of all criteria) by three experts.

\begin{tabular}{lllcccc}
\hline & $C_{1}$ & $C_{2}$ & $C_{3}$ & $C_{4}$ & $C_{5}$ & $C_{6}$ \\
\hline$E_{1}$ & $\mathrm{EH}$ & $\mathrm{H}$ & $\mathrm{H}$ & $\mathrm{H}$ & $\mathrm{EH}$ & $\mathrm{F}$ \\
$E_{2}$ & $\mathrm{EH}$ & $\mathrm{H}$ & $\mathrm{H}$ & $\mathrm{MH}$ & $\mathrm{H}$ & $\mathrm{H}$ \\
$E_{3}$ & $\mathrm{EH}$ & $\mathrm{EH}$ & $\mathrm{VH}$ & $\mathrm{EH}$ & $\mathrm{VH}$ & $\mathrm{H}$ \\
\hline
\end{tabular}

Table 5: Transfer to the linguistic variable of type 2.

\begin{tabular}{|c|c|c|c|c|c|}
\hline Stock & Criterion & $E_{1}$ & $E_{1}$ & $E_{1}$ & Average \\
\hline \multirow{10}{*}{$C_{1}$} & $S_{1}$ & $S_{3}^{7}, 0.0000$ & $S_{3}^{7}, 0.0000$ & $S_{5}^{7},-0.0833$ & $S_{4^{\prime}}^{7}-0.0833$ \\
\hline & $S_{2}$ & $S_{2}^{7},-0.0833$ & $S_{3}^{7}, 0.0000$ & $S_{4^{\prime}}^{7}-0.0417$ & $S_{3}^{7},-0.0417$ \\
\hline & $S_{3}$ & $S_{3}^{7}, 0.0000$ & $S_{3}^{7}, 0.0000$ & $S_{5}^{7},-0.0833$ & $S_{4^{\prime}}^{7}-0.0833$ \\
\hline & $S_{4}$ & $S_{3}^{7}, 0.0000$ & $S_{5}^{7}, 0.0000$ & $S_{4}^{7},-0.0417$ & $S_{4^{\prime}}^{7}-0.0139$ \\
\hline & $S_{5}$ & $S_{3}^{7}, 0.0000$ & $S_{4}^{7}, 0.0000$ & $S_{6}^{7}, 0.0000$ & $S_{4}^{7}, 0.0556$ \\
\hline & $S_{6}$ & $S_{2}^{7},-0.0833$ & $S_{3}^{7}, 0.0000$ & $S_{5}^{7},-0.0833$ & $S_{3}^{7}, 0.0000$ \\
\hline & $S_{7}$ & $S_{5}^{7},-0.0833$ & $S_{3}^{7}, 0.0000$ & $S_{5}^{7},-0.0833$ & $S_{4}^{7}, 0.0000$ \\
\hline & $S_{8}$ & $S_{0}^{7}, 0.0000$ & $S_{4}^{7}, 0.0000$ & $S_{5}^{7},-0.0833$ & $S_{3}^{7},-0.0278$ \\
\hline & $S_{9}$ & $S_{5}^{7},-0.0833$ & $S_{4}^{7}, 0.0000$ & $S_{5}^{7}, 0.0417$ & $S_{5}^{7},-0.0694$ \\
\hline & $S_{10}$ & $S_{0}^{7}, 0.0000$ & $S_{5}^{7}, 0.0000$ & $S_{5}^{7},-0.0833$ & $S_{3}^{7}, 0.0278$ \\
\hline \multirow{10}{*}{$C_{2}$} & $S_{1}$ & $S_{6}^{7}, 0.0000$ & $S_{4}^{7}, 0.0000$ & $S_{5}^{7}, 0.0417$ & $S_{5}^{7}, 0.0139$ \\
\hline & $S_{2}$ & $S_{3}^{7}, 0.0000$ & $S_{4}^{7}, 0.0000$ & $S_{5}^{7},-0.0833$ & $S_{4}^{7},-0.0278$ \\
\hline & $S_{3}$ & $S_{5}^{7},-0.0833$ & $S_{3}^{7}, 0.0000$ & $S_{4^{\prime}}^{7}-0.0417$ & $S_{4}^{7},-0.0417$ \\
\hline & $S_{4}$ & $S_{5}^{7},-0.0833$ & $S_{5}^{7}, 0.0000$ & $S_{5}^{7},-0.0833$ & $S_{5}^{7},-0.0556$ \\
\hline & $S_{5}$ & $S_{5}^{7},-0.0833$ & $S_{4}, 0.0000$ & $S_{5}^{7}, 0.0417$ & $S_{5}^{7},-0.0694$ \\
\hline & $S_{6}$ & $S_{5}^{7},-0.0833$ & $S_{3}^{7}, 0.0000$ & $S_{5}^{7}, 0.0417$ & $S_{4}^{7}, 0.0417$ \\
\hline & $S_{7}$ & $S_{2}^{7},-0.0833$ & $S_{4^{\prime}}^{7}, 0.0000$ & $S_{5}^{7}, 0.0417$ & $S_{4^{\prime}}^{7}-0.0694$ \\
\hline & $S_{8}$ & $S_{3}^{7}, 0.0000$ & $S_{3}^{7}, 0.0000$ & $S_{5}^{7}, 0.0417$ & $S_{4}^{7},-0.0417$ \\
\hline & $S_{9}$ & $S_{3}^{7}, 0.0000$ & $S_{4}, 0.0000$ & $S_{5}^{7},-0.0833$ & $S_{4}^{7},-0.0278$ \\
\hline & $S_{10}$ & $S_{3}^{7}, 0.0000$ & $S_{5}^{7}, 0.0000$ & $S_{5}^{7},-0.0833$ & $S_{4}^{7}, 0.0278$ \\
\hline \multirow{10}{*}{$C_{3}$} & $S_{1}$ & $S_{5}^{7},-0.0833$ & $S_{4}^{7}, 0.0000$ & $S_{5}^{7}, 0.0417$ & $S_{5}^{7},-0.0694$ \\
\hline & $S_{2}$ & $S_{3}^{7}, 0.0000$ & $S_{3}^{7}, 0.0000$ & $S_{5}^{7},-0.0833$ & $S_{4}^{7},-0.0833$ \\
\hline & $S_{3}$ & $S_{3}^{7}, 0.0000$ & $S_{4}^{7}, 0.0000$ & $S_{5}^{7},-0.0833$ & $S_{4}^{7},-0.0278$ \\
\hline & $S_{4}$ & $S_{3}^{7}, 0.0000$ & $S_{4}^{7}, 0.0000$ & $S_{4}^{7},-0.0417$ & $S_{4^{\prime}}^{7}-0.0694$ \\
\hline & $S_{5}$ & $S_{3}^{7}, 0.0000$ & $S_{5}^{7}, 0.0000$ & $S_{5}^{7},-0.0833$ & $S_{4}^{7}, 0.0278$ \\
\hline & $S_{6}$ & $S_{3}^{7}, 0.0000$ & $S_{3}^{7}, 0.0000$ & $S_{5}^{7}, 0.0417$ & $S_{4^{\prime}}^{7}-0.0417$ \\
\hline & $S_{7}$ & $S_{3}^{7}, 0.0000$ & $S_{3}^{7}, 0.0000$ & $S_{5}^{7},-0.0833$ & $S_{4}^{7},-0.0833$ \\
\hline & $S_{8}$ & $S_{0}^{7}, 0.0000$ & $S_{3}^{7}, 0.0000$ & $S_{5}^{7}, 0.0417$ & $S_{3}^{7},-0.0417$ \\
\hline & $S_{9}$ & $S_{3}^{7}, 0.0000$ & $S_{3}^{7}, 0.0000$ & $S_{5}^{7}, 0.0417$ & $S_{4^{\prime}}^{7}-0.0417$ \\
\hline & $S_{10}$ & $S_{3}^{7}, 0.0000$ & $S_{4^{\prime}}^{7}, 0.0000$ & $S_{4}^{7},-0.0417$ & $S_{4}^{7},-0.0694$ \\
\hline
\end{tabular}


Journal of Applied Mathematics and Decision Sciences

Table 5: Continued.

\begin{tabular}{|c|c|c|c|c|c|}
\hline Stock & Criterion & $E_{1}$ & $E_{1}$ & $E_{1}$ & Average \\
\hline \multirow{9}{*}{$C_{4}$} & $S_{1}$ & $S_{2}^{7},-0.0833$ & $S_{3}^{7}, 0.0000$ & $S_{6}^{7}, 0.0000$ & $S_{4}^{7},-0.0833$ \\
\hline & $S_{2}$ & $S_{0}^{7}, 0.0000$ & $S_{3}^{7}, 0.0000$ & $S_{4}^{7},-0.0417$ & $S_{2}^{7}, 0.0417$ \\
\hline & $S_{3}$ & $S_{3}^{7}, 0.0000$ & $S_{3}^{7}, 0.0000$ & $S_{4}^{7},-0.0417$ & $S_{3}^{7}, 0.0417$ \\
\hline & $S_{4}$ & $S_{3}^{7}, 0.0000$ & $S_{5}^{7}, 0.0000$ & $S_{5}^{7},-0.0833$ & $S_{4}^{7}, 0.0278$ \\
\hline & $S_{5}$ & $S_{5}^{7},-0.0833$ & $S_{4}^{7}, 0.0000$ & $S_{5}^{7}, 0.0417$ & $S_{5}^{7},-0.0694$ \\
\hline & $S_{6}$ & $S_{2}^{7},-0.0833$ & $S_{4}^{7}, 0.0000$ & $S_{5}^{7}, 0.0417$ & $S_{4}^{7},-0.0694$ \\
\hline & $S_{7}$ & $S_{3}^{7}, 0.0000$ & $S_{3}^{7}, 0.0000$ & $S_{5}^{7}, 0.0417$ & $S_{4}^{7},-0.0417$ \\
\hline & $S_{8}$ & $S_{0}^{7}, 0.0000$ & $S_{4}^{7}, 0.0000$ & $S_{6}^{7}, 0.0000$ & $S_{3}^{7}, 0.0556$ \\
\hline & $S_{9}$ & $S_{3}^{7}, 0.0000$ & $S_{4}^{7}, 0.0000$ & $S_{5}^{7}, 0.0417$ & $S_{4}^{7}, 0.0139$ \\
\hline \multirow{11}{*}{$C_{5}$} & $S_{10}$ & $S_{0}^{7}, 0.0000$ & $S_{4}^{7}, 0.0000$ & $S_{5}^{7},-0.0833$ & $S_{3}^{7},-0.0278$ \\
\hline & $S_{1}$ & $S_{3}^{7}, 0.0000$ & $S_{5}^{7}, 0.0000$ & $S_{5}^{7}, 0.0417$ & $S_{4}^{7}, 0.0694$ \\
\hline & $S_{2}$ & $S_{2}^{7},-0.0833$ & $S_{4}^{7}, 0.0000$ & $S_{5}^{7}, 0.0417$ & $S_{4^{\prime}}^{7}-0.0694$ \\
\hline & $S_{3}$ & $S_{2}^{7},-0.0833$ & $S_{4}^{7}, 0.0000$ & $S_{5}^{7},-0.0833$ & $S_{3}^{7}, 0.0556$ \\
\hline & $S_{4}$ & $S_{3}^{7}, 0.0000$ & $S_{4}^{7}, 0.0000$ & $S_{4^{\prime}}^{7}-0.0417$ & $S_{4^{\prime}}^{7}-0.0694$ \\
\hline & $S_{5}$ & $S_{5}^{7},-0.0833$ & $S_{4}^{7}, 0.0000$ & $S_{5}^{7}, 0.0417$ & $S_{5}^{7},-0.0694$ \\
\hline & $S_{6}$ & $S_{3}^{7}, 0.0000$ & $S_{3}^{7}, 0.0000$ & $S_{5}^{7},-0.0833$ & $S_{4}^{7},-0.0833$ \\
\hline & $S_{7}$ & $S_{2}^{7},-0.0833$ & $S_{4}^{7}, 0.0000$ & $S_{5}^{7}, 0.0417$ & $S_{4,}^{7}-0.0694$ \\
\hline & $S_{8}$ & $S_{0}^{7}, 0.0000$ & $S_{4}^{7}, 0.0000$ & $S_{5}^{7}, 0.0417$ & $S_{3}^{7}, 0.0139$ \\
\hline & $S_{9}$ & $S_{3}^{7}, 0.0000$ & $S_{4}^{7}, 0.0000$ & $S_{5}^{7}, 0.0417$ & $S_{4}^{7}, 0.0139$ \\
\hline & $S_{10}$ & $S_{0}^{7}, 0.0000$ & $S_{3}^{7}, 0.0000$ & $S_{4}^{7}-0.0417$ & $S_{2}^{7}, 0.0417$ \\
\hline \multirow{10}{*}{$C_{6}$} & $S_{1}$ & $S_{2}^{7},-0.0833$ & $S_{4}^{7}, 0.0000$ & $S_{5}^{7}, 0.0417$ & $S_{4}^{7},-0.0694$ \\
\hline & $S_{2}$ & $S_{2}^{7},-0.0833$ & $S_{4}^{7}, 0.0000$ & $S_{5}^{7},-0.0833$ & $S_{3}^{7}, 0.0556$ \\
\hline & $S_{3}$ & $S_{3}^{7}, 0.0000$ & $S_{4}^{7}, 0.0000$ & $S_{4^{\prime}}^{7}-0.0417$ & $S_{4^{\prime}}^{7}-0.0694$ \\
\hline & $S_{4}$ & $S_{2}^{7},-0.0833$ & $S_{6}^{7}, 0.0000$ & $S_{4}^{7}-0.0417$ & $S_{4}^{7},-0.0417$ \\
\hline & $S_{5}$ & $S_{2}^{7},-0.0833$ & $S_{5}^{7}, 0.0000$ & $S_{5}^{7},-0.0833$ & $S_{4,}^{7}-0.0556$ \\
\hline & $S_{6}$ & $S_{3}^{7}, 0.0000$ & $S_{3}^{7}, 0.0000$ & $S_{5}^{7},-0.0833$ & $S_{4,}^{7}-0.0833$ \\
\hline & $S_{7}$ & $S_{3}^{7}, 0.0000$ & $S_{4}^{7}, 0.0000$ & $S_{5}^{7}, 0.0417$ & $S_{4}^{7}, 0.0139$ \\
\hline & $S_{8}$ & $S_{2}^{7},-0.0833$ & $S_{4}^{7}, 0.0000$ & $S_{5}^{7}, 0.0417$ & $S_{4}^{7},-0.0694$ \\
\hline & $S_{9}$ & $S_{3}^{7}, 0.0000$ & $S_{5}^{7}, 0.0000$ & $S_{5}^{7},-0.0833$ & $S_{4}^{7}, 0.0278$ \\
\hline & $S_{10}$ & $S_{0}^{7}, 0.0000$ & $S_{4}^{7}, 0.0000$ & $S_{4}^{7},-0.0417$ & $S_{3}^{7},-0.0694$ \\
\hline
\end{tabular}

Table 6: Transfer to the linguistic variable of type 2.

\begin{tabular}{lcccc}
\hline Criterion & $E_{1}$ & $E_{2}$ & $E_{3}$ & Average \\
\hline$C_{1}$ & $S_{6}^{7}, 0.0000$ & $S_{6}^{7}, 0.0000$ & $S_{6}^{7}, 0.0000$ & $S_{6}^{7}, 0.0000$ \\
$C_{2}$ & $S_{5}^{7},-0.0833$ & $S_{5}^{7}, 0.0000$ & $S_{6}^{7}, 0.0000$ & $S_{5}^{7}, 0.0278$ \\
$C_{3}$ & $S_{5}^{7},-0.0833$ & $S_{5}^{7}, 0.0000$ & $S_{5}^{7}, 0.0417$ & $S_{5}^{7},-0.0139$ \\
$C_{4}$ & $S_{5}^{7},-0.0833$ & $S_{4}^{7}, 0.0000$ & $S_{6}^{7}, 0.0000$ & $S_{5}^{7},-0.0278$ \\
$C_{5}$ & $S_{6}^{7}, 0.0000$ & $S_{5}^{7}, 0.0000$ & $S_{5}^{7}, 0.0417$ & $S_{5}^{7}, 0.0694$ \\
$C_{6}$ & $S_{3}^{7}, 0.0000$ & $S_{5}^{7}, 0.0000$ & $S_{5}^{7},-0.0833$ & $S_{4}^{7}, 0.0278$ \\
\hline
\end{tabular}


Table 7: The weighted linguistic decision matrix.

\begin{tabular}{lcccccc}
\hline & $C_{1}$ & $C_{2}$ & $C_{3}$ & $C_{4}$ & $C_{5}$ & $C_{6}$ \\
\hline$S_{1}$ & 0.1148 & 0.1435 & 0.1231 & 0.0924 & 0.1307 & 0.0816 \\
$S_{2}$ & 0.0902 & 0.1082 & 0.0940 & 0.0594 & 0.1061 & 0.0759 \\
$S_{3}$ & 0.1148 & 0.1059 & 0.1030 & 0.0858 & 0.0987 & 0.0816 \\
$S_{4}$ & 0.1284 & 0.1318 & 0.0963 & 0.1100 & 0.1061 & 0.0854 \\
$S_{5}$ & 0.1421 & 0.1294 & 0.1119 & 0.1211 & 0.1357 & 0.0835 \\
$S_{6}$ & 0.0984 & 0.1200 & 0.1008 & 0.0946 & 0.1036 & 0.0797 \\
$S_{7}$ & 0.1311 & 0.1012 & 0.0940 & 0.0990 & 0.1061 & 0.0930 \\
$S_{8}$ & 0.0929 & 0.1059 & 0.0739 & 0.0880 & 0.0913 & 0.0816 \\
$S_{9}$ & 0.1503 & 0.1082 & 0.1008 & 0.1078 & 0.1209 & 0.0949 \\
$S_{10}$ & 0.1038 & 0.1176 & 0.0963 & 0.0748 & 0.0666 & 0.0588 \\
\hline
\end{tabular}

Table 8: Linguistic positive-ideal solution (LPIS, $S^{*}$ ) and linguistic negative-ideal solution (LNIS, $S^{-}$).

\begin{tabular}{lcccccr}
\hline & $C_{1}$ & $C_{2}$ & $C_{3}$ & $C_{4}$ & $C_{5}$ & $C_{6}$ \\
\hline$S^{*}$ & 0.1503 & 0.1435 & 0.1231 & 0.1211 & 0.1357 & 0.0949 \\
$S^{-}$ & 0.0902 & 0.1012 & 0.0739 & 0.0594 & 0.0666 & 0.0588 \\
\hline
\end{tabular}

Table 9: Calculate the distance from $S^{*}$ and the distance from $S^{-}$, the closeness coefficient of each stock.

\begin{tabular}{lcccccccccc}
\hline & $S_{1}$ & $S_{2}$ & $S_{3}$ & $S_{4}$ & $S_{5}$ & $S_{6}$ & $S_{7}$ & $S_{8}$ & $S_{9}$ & $S_{10}$ \\
\hline$d^{*}$ & 0.0478 & 0.1036 & 0.0766 & 0.0492 & 0.0228 & 0.0755 & 0.0661 & 0.1018 & 0.0463 & 0.1084 \\
$d^{-}$ & 0.1027 & 0.0480 & 0.0610 & 0.0879 & 0.1188 & 0.0647 & 0.0799 & 0.0444 & 0.1048 & 0.0346 \\
$\mathrm{CC}$ & 0.6826 & 0.3166 & 0.4432 & 0.6409 & 0.8388 & 0.4614 & 0.5471 & 0.3038 & 0.6937 & 0.2419 \\
\hline
\end{tabular}

Table 10: The overall concordance matrix.

\begin{tabular}{lcccccccccc}
\hline & $S_{1}$ & $S_{2}$ & $S_{3}$ & $S_{4}$ & $S_{5}$ & $S_{6}$ & $S_{7}$ & $S_{8}$ & $S_{9}$ & $S_{10}$ \\
\hline$S_{1}$ & 1.0000 & 1.0000 & 1.0000 & 1.0000 & 0.9868 & 1.0000 & 1.0000 & 1.0000 & 0.9836 & 1.0000 \\
$S_{2}$ & 0.9046 & 1.0000 & 1.0000 & 0.8219 & 0.7268 & 0.9472 & 0.8716 & 0.9868 & 0.7040 & 1.0000 \\
$S_{3}$ & 0.9287 & 1.0000 & 1.0000 & 1.0000 & 0.9028 & 1.0000 & 1.0000 & 1.0000 & 0.9836 & 1.0000 \\
$S_{4}$ & 1.0000 & 1.0000 & 1.0000 & 1.0000 & 1.0000 & 1.0000 & 1.0000 & 1.0000 & 1.0000 & 1.0000 \\
$S_{5}$ & 1.0000 & 1.0000 & 1.0000 & 1.0000 & 1.0000 & 1.0000 & 1.0000 & 1.0000 & 1.0000 & 1.0000 \\
$S_{6}$ & 1.0000 & 1.0000 & 1.0000 & 1.0000 & 0.9196 & 1.0000 & 1.0000 & 1.0000 & 0.8852 & 1.0000 \\
$S_{7}$ & 0.9019 & 1.0000 & 1.0000 & 0.9859 & 1.0000 & 1.0000 & 1.0000 & 1.0000 & 1.0000 & 1.0000 \\
$S_{8}$ & 0.7500 & 1.0000 & 0.9866 & 0.9836 & 0.7061 & 1.0000 & 0.9672 & 1.0000 & 0.8525 & 1.0000 \\
$S_{9}$ & 0.9577 & 1.0000 & 1.0000 & 1.0000 & 1.0000 & 1.0000 & 1.0000 & 1.0000 & 1.0000 & 1.0000 \\
$S_{10}$ & 0.6257 & 0.7441 & 0.7885 & 0.6685 & 0.4954 & 0.7589 & 0.6758 & 0.8033 & 0.5360 & 0.8033 \\
\hline
\end{tabular}

Step 5. Transform the linguistic evaluations of weight of each criterion into the linguistic variables of type 2 and aggregate the linguistic weight of each criterion as Table 6.

Step 6. Calculate the weighted linguistic decision matrix $V=\left[v_{i j}\right]_{m * n}$ as Table 7.

Step 7. Calculate the linguistic positive-ideal solution (LPIS, $S^{*}$ ) and linguistic negative-ideal solution (LNIS, $S^{-}$) as Table 8 . 
Table 11: The credibility matrix.

\begin{tabular}{ccccccccccc}
\hline & $S_{1}$ & $S_{2}$ & $S_{3}$ & $S_{4}$ & $S_{5}$ & $S_{6}$ & $S_{7}$ & $S_{8}$ & $S_{9}$ & $S_{10}$ \\
\hline$S_{1}$ & 1.0000 & 1.0000 & 1.0000 & 1.0000 & 0.9868 & 1.0000 & 1.0000 & 1.0000 & 0.9836 & 1.0000 \\
$S_{2}$ & 0.9046 & 1.0000 & 1.0000 & 0.8219 & 0.4845 & 0.9472 & 0.8716 & 0.9868 & 0.7040 & 1.0000 \\
$S_{3}$ & 0.9287 & 1.0000 & 1.0000 & 1.0000 & 0.9028 & 1.0000 & 1.0000 & 1.0000 & 0.9836 & 1.0000 \\
$S_{4}$ & 1.0000 & 1.0000 & 1.0000 & 1.0000 & 1.0000 & 1.0000 & 1.0000 & 1.0000 & 1.0000 & 1.0000 \\
$S_{5}$ & 1.0000 & 1.0000 & 1.0000 & 1.0000 & 1.0000 & 1.0000 & 1.0000 & 1.0000 & 1.0000 & 1.0000 \\
$S_{6}$ & 1.0000 & 1.0000 & 1.0000 & 1.0000 & 0.9196 & 1.0000 & 1.0000 & 1.0000 & 0.8852 & 1.0000 \\
$S_{7}$ & 0.9019 & 1.0000 & 1.0000 & 0.9859 & 1.0000 & 1.0000 & 1.0000 & 1.0000 & 1.0000 & 1.0000 \\
$S_{8}$ & 0.7500 & 1.0000 & 0.9866 & 0.9836 & 0.7061 & 1.0000 & 0.9672 & 1.0000 & 0.8525 & 1.0000 \\
$S_{9}$ & 0.9577 & 1.0000 & 1.0000 & 1.0000 & 1.0000 & 1.0000 & 1.0000 & 1.0000 & 1.0000 & 1.0000 \\
$S_{10}$ & 0.5213 & 0.7440 & 0.7884 & 0.6684 & 0.3302 & 0.7588 & 0.6757 & 0.8032 & 0.5359 & 0.8032 \\
\hline
\end{tabular}

Table 12: The concordance credibility degree, the discordance credibility degree, the net credibility degree, and the outranking index.

\begin{tabular}{lcccc}
\hline Stock & $\phi^{+}\left(S_{i}\right)$ & $\phi^{-}\left(S_{i}\right)$ & $\phi\left(S_{i}\right)$ & OTI \\
\hline$S_{1}$ & 9.9704 & 8.9641 & 1.0063 & 0.5559 \\
$S_{2}$ & 8.7206 & 9.7440 & -1.0234 & 0.4431 \\
$S_{3}$ & 9.8151 & 9.7750 & 0.0402 & 0.5022 \\
$S_{4}$ & 10.0000 & 9.4599 & 0.5401 & 0.5300 \\
$S_{5}$ & 10.0000 & 8.3300 & 1.6700 & 0.5928 \\
$S_{6}$ & 9.8049 & 9.7060 & 0.0989 & 0.5055 \\
$S_{7}$ & 9.8878 & 9.5145 & 0.3732 & 0.5207 \\
$S_{8}$ & 9.2459 & 9.7900 & -0.5441 & 0.4698 \\
$S_{9}$ & 9.9577 & 8.9448 & 1.0128 & 0.5563 \\
$S_{10}$ & 6.6292 & 9.8032 & -3.1740 & 0.3237 \\
\hline
\end{tabular}

Table 13: Compute the ratio of investment in accordance with the risk preference.

\begin{tabular}{lccccc}
\hline Rank & $P_{t}\left(S_{i}\right)$ & $P_{e}\left(S_{i}\right)$ & $P_{\mathrm{RA}}\left(S_{i}\right)$ & $P_{\mathrm{RN}}\left(S_{i}\right)$ & $P_{\mathrm{RL}}\left(s_{i}\right)$ \\
\hline 1 & $S_{5}, 0.2465$ & $S_{5}, 0.1575$ & $S_{5}, 0.2225$ & $S_{5}, 0.2308$ & $S_{5}, 0.2385$ \\
2 & $S_{9}, 0.2038$ & $S_{9}, 0.1478$ & $S_{9}, 0.2088$ & $S_{9}, 0.2028$ & $S_{9}, 0.1973$ \\
3 & $S_{1}, 0.2006$ & $S_{1}, 0.1477$ & $S_{1}, 0.2075$ & $S_{1}, 0.2012$ & $S_{1}, 0.1952$ \\
4 & $S_{4}, 0.1883$ & $S_{4}, 0.1408$ & $S_{4}, 0.1948$ & $S_{4}, 0.1903$ & $S_{4}, 0.1861$ \\
5 & $S_{7}, 0.1608$ & $S_{7}, 0.1384$ & $S_{7}, 0.1663$ & $S_{7}, 0.1749$ & $S_{7}, 0.1829$ \\
6 & & $S_{6}, 0.1343$ & & & \\
7 & & $S_{3}, 0.1335$ & & & \\
\hline
\end{tabular}

Step 8. Calculate the distance of each stock from $S^{*}$ and the distance from $S^{-}$, and the closeness coefficient of each stock as Table 9.

Step 9. Define investment threshold value as the average of the closeness coefficient $\beta_{t}=$ $\sum_{i=1}^{n} \mathrm{CC}\left(S_{i}\right) / n$, so the investment portfolio set is $\Omega_{t}=\left\{S_{1}, S_{4}, S_{5}, S_{7}, S_{9}\right\}$ in accordance with TOPSIS. The ratio of investment based on TOPSISmethod is shown as Table 13. 
Step 10. The indifference threshold, preference threshold, and veto threshold values of each criterion can be determined in accordance with the linguistic variables of type 2 as

$$
\begin{gathered}
q_{j}=\Delta^{-1}\left(S_{1}^{7}\right)-\Delta^{-1}\left(S_{0}^{7}\right)=\frac{1}{6}, \quad p_{j}=\Delta^{-1}\left(S_{2}^{7}\right)-\Delta^{-1}\left(S_{0}^{7}\right)=\frac{2}{6}, \\
v_{j}=\Delta^{-1}\left(S_{3}^{7}\right)-\Delta^{-1}\left(S_{0}^{7}\right)=\frac{3}{6}, \quad j=1, \ldots, 6 .
\end{gathered}
$$

Step 11. Calculate the concordance matrix and the discordance matrix of each pair stock with respect to each criterion.Then, calculate the overall concordance matrix as Table 10 and the credibility matrix as Table 11.

Step 12. Calculate the concordance credibility degree, the discordance credibility degree, the net credibility degree, and the outranking index as Table 12 .

Step 13. Define investment threshold value as the average of the outranking index $\beta_{e}=$ $\sum_{i=1}^{n} \operatorname{OTI}\left(S_{i}\right) / n$, so the investment portfolio set is $\Omega_{e}=\left\{S_{1}, S_{3}, S_{4}, S_{5}, S_{6}, S_{7}, S_{9}\right\}$ in accordance with ELECTRE method. The ratio of investment based on ELECTRE method is shown as Table 13.

Step 14. Compute strict stock portfolio set as $\Omega_{i p}=\Omega_{t} \cap \Omega_{e}=\left\{S_{1}, S_{4}, S_{5}, S_{7}, S_{9}\right\}$.

Step 15. According to the investment preference of investor, the result of the ratio of investment based on combining linguistic ELECTRE with TOPSIS can be calculated as Table 13.

According to the result of numerical example, experts considered that the proposed method is useful to help investor determine the stock portfolio.

\section{Conclusion}

In general, the stock portfolio decision problem adheres to uncertain and imprecise data, and fuzzy set theory is adequate to deal with it. In this proposed model, different types of 2-tuple linguistic variables are applied to express the subjective judgment of each expert. Expert can easily express his opinion by different types of 2-tuple linguistic variables. The generalized translation method of different types of 2-tuple linguistic variables is applied to aggregate the subjective judgment of each expert. It is a flexible way to aggregate the opinions of all experts. Then, a new decision-making method has been presented in this paper by combining the advantages of ELECTRE with TOPSIS methods. According to the experts' opinions, the linguistic ELECTRE method and linguistic TOPSIS method are used to derive the closeness coefficient and the outranking index of each stock, respectively. Based on the closeness coefficient, the outranking index, and selection threshold, we can easily obtain three type of the investment ratio in accordance with different investment preference of final decision-maker. It is a reasonable way in real decision environment. In other words, the proposed method provides a flexible way to determine the stock portfolio under the uncertain environment. In the future, the concept of combing different decision methods for deciding stock portfolio will be applied to different fields such as R\&D projects investment, bonus distribution in a company. A decision support system will be developed based on the proposed method for dealing with the stock selection problems in the future. 


\section{References}

[1] X. Huang, "Portfolio selection with a new definition of risk," European Journal of Operational Research, vol. 186, no. 1, pp. 351-357, 2008.

[2] H. Markowitz, "Portfolio selection," Journal of Finance, pp. 77-91, 1952.

[3] C. A. Magni, "Correct or incorrect application of CAPM? Correct or incorrect decisions with CAPM?" European Journal of Operational Research, vol. 192, no. 2, pp. 549-560, 2009.

[4] F. Tiryaki and M. Ahlatcioglu, "Fuzzy stock selection using a new fuzzy ranking and weighting algorithm," Applied Mathematics and Computation, vol. 170, no. 1, pp. 144-157, 2005.

[5] E. F. Fama and K. R. French, "The cross-section of expected stock returns," Journal of Finance, vol. 47, pp. 427-465, 1992.

[6] C. D. Feinstein and M. N. Thapa, "Notes: a reformulation of a mean-absolute deviation portfolio optimization model," Management Sciences, vol. 39, no. 12, pp. 1552-1553, 1993.

[7] W. F. Sharpe, G. J. Alexander, and J. F. Bailey, Investments, Prentice-Hall, Englewood Cliffs, NJ, USA, 6th edition, 1999.

[8] T. L. Saaty, P. C. Rogers, and R. Bell, "Portfolio selection through hierarchies," Journal of Portfolio Manage, pp. 16-21, 1980.

[9] N. C. P. Edirisinghe and X. Zhang, "Generalized DEA model of fundamental analysis and its application to portfolio optimization," Journal of Banking $\mathcal{E}$ Finance, vol. 31, no. 11, pp. 3311-3335, 2007.

[10] F. Ben Abdelaziz, B. Aouni, and R. El Fayedh, "Multi-objective stochastic programming for portfolio selection," European Journal of Operational Research, vol. 177, no. 3, pp. 1811-1823, 2007.

[11] E. Ballestero, "Stochastic goal programming: a mean-variance approach," European Journal of Operational Research, vol. 131, no. 3, pp. 476-481, 2001.

[12] B. Aouni, F. Ben Abdelaziz, and J.-M. Martel, "Decision-maker's preferences modeling in the stochastic goal programming," European Journal of Operational Research, vol. 162, no. 3, pp. 610-618, 2005.

[13] C. L. Hwang and K. Yoon, Multiple Attribute Decision Making Methods and Applications, vol. 186 of Lecture Notes in Economics and Mathematical Systems, Springer, Berlin, Germany, 1981.

[14] A. Papadopoulos and A. Karagiannidis, "Application of the multi-criteria analysis method Electre III for the optimisation of decentralised energy systems," Omega, vol. 36, no. 5, pp. 766-776, 2008.

[15] C.-T. Chen, "Extensions of the TOPSIS for group decision-making under fuzzy environment," Fuzzy Sets and Systems, vol. 114, no. 1, pp. 1-9, 2000.

[16] F. Herrera and E. Herrera-Viedma, "Linguistic decision analysis: steps for solving decision problems under linguistic information," Fuzzy Sets and Systems, vol. 115, no. 1, pp. 67-82, 2000.

[17] F. Herrera and L. Martinez, "A 2-tuple fuzzy linguistic representation model for computing with words," IEEE Transactions on Fuzzy Systems, vol. 8, no. 6, pp. 746-752, 2000.

[18] Z. Xu, "Deviation measures of linguistic preference relations in group decision making," Omega, vol. 33, no. 3, pp. 249-254, 2005.

[19] E. Herrera-Viedma, O. Cordón, M. Luque, A. G. Lopez, and A. M. Muñoz, "A model of fuzzy linguistic IRS based on multi-granular linguistic information," International Journal of Approximate Reasoning, vol. 34, no. 2-3, pp. 221-239, 2003.

[20] F. Herrera, L. Martinez, and P. J. Sanchez, "Managing non-homogeneous information in group decision making," European Journal of Operational Research, vol. 166, no. 1, pp. 115-132, 2005.

[21] L. A. Zadeh, "Fuzzy sets," Information and Control, vol. 8, no. 3, pp. 338-353, 1965.

[22] R. R. Yager, "An approach to ordinal decision making," International Journal of Approximate Reasoning, vol. 12, no. 3-4, pp. 237-261, 1995.

[23] C.-T. Lin and Y.-T. Chen, "Bid/no-bid decision-making-a fuzzy linguistic approach," International Journal of Project Management, vol. 22, no. 7, pp. 585-593, 2004.

[24] R.-C. Wang and S.-J. Chuu, "Group decision-making using a fuzzy linguistic approach for evaluating the flexibility in a manufacturing system," European Journal of Operational Research, vol. 154, no. 3, pp. 563-572, 2004.

[25] E. Herrera-Viedma and E. Peis, "Evaluating the informative quality of documents in SGML format from judgements by means of fuzzy linguistic techniques based on computing with words," Information Processing and Management, vol. 39, no. 2, pp. 233-249, 2003. 
[26] L. A. Zadeh, "The concept of a linguistic variable and its application to approximate reasoning-I," Information Sciences, vol. 8, pp. 199-249, 1975.

[27] L. A. Zadeh, "The concept of a linguistic variable and its application to approximate reasoning-II," Information Sciences, vol. 8, pp. 301-357, 1975.

[28] A. Kaufmann and M. M. Gupta, Introduction to Fuzzy Arithmetic: Theory and Applications, Van Nostrand Reinhold, New York, NY, USA, 1991.

[29] F. Herrera and L. Martinez, "A model based on linguistic 2-tuples for dealing with multigranular hierarchical linguistic contexts in multi-expert decision-making," IEEE Transactions on Systems, Man, and Cybernetics, Part B, vol. 31, no. 2, pp. 227-234, 2001.

[30] W.-S. Tai and C.-T. Chen, "A new evaluation model for intellectual capital based on computing with linguistic variable," Expert Systems with Applications, vol. 36, no. 2, pp. 3483-3488, 2009.

[31] E. Herrera-Viedma, F. Herrera, L. Martínez, J. C. Herrera, and A. G. López, "Incorporating filtering techniques in a fuzzy linguistic multi-agent model for information gathering on the web," Fuzzy Sets and Systems, vol. 148, no. 1, pp. 61-83, 2004.

[32] H.-F. Li and J.-J. Wang, "An improved ranking method for ELECTRE III," in International Conference on Wireless Communications, Networking and Mobile Computing (WiCOM '07), pp. 6659-6662, 2007. 


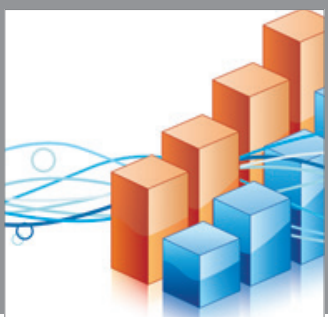

Advances in

Operations Research

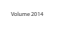

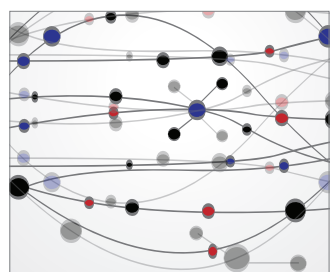

\section{The Scientific} World Journal
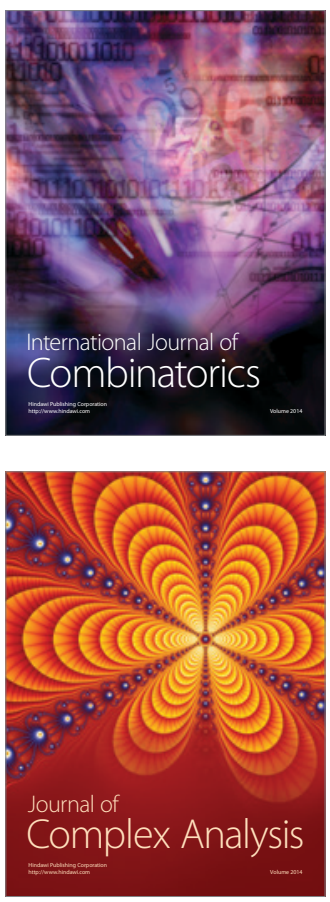

International Journal of

Mathematics and

Mathematical

Sciences
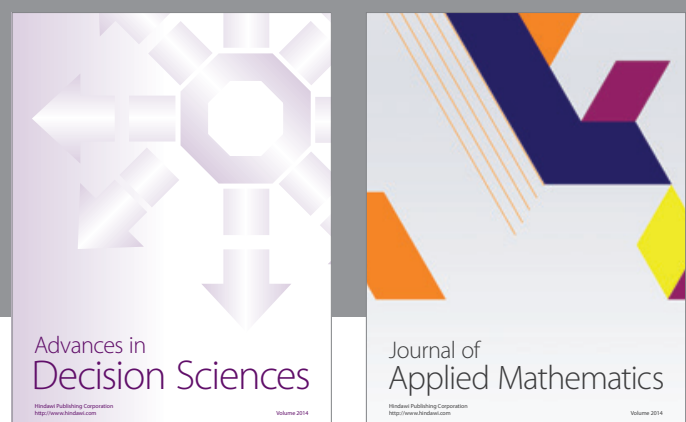

Journal of

Applied Mathematics
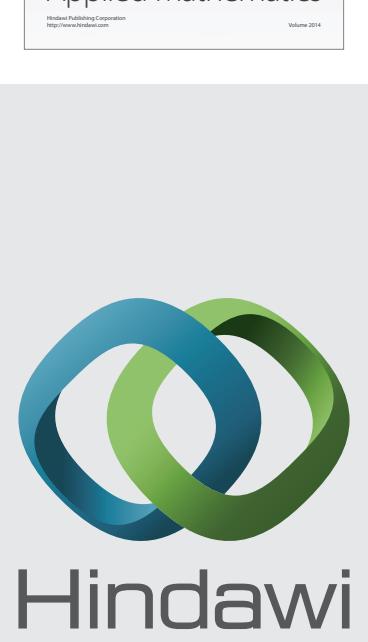

Submit your manuscripts at http://www.hindawi.com
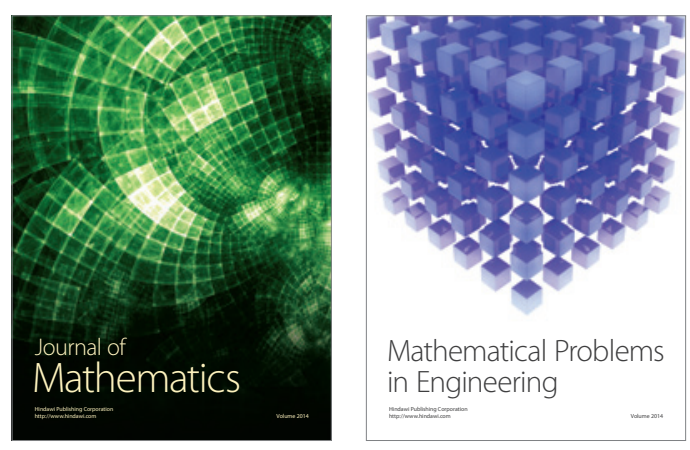

Mathematical Problems in Engineering
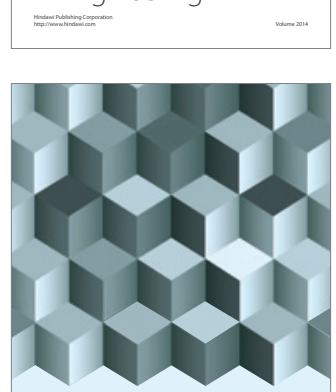

Journal of

Function Spaces
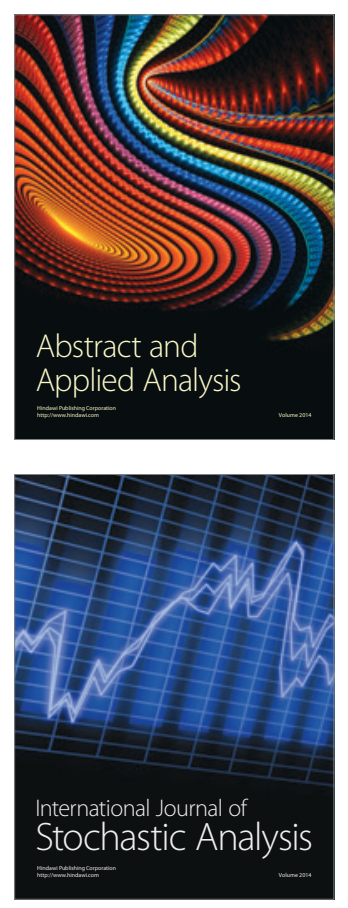

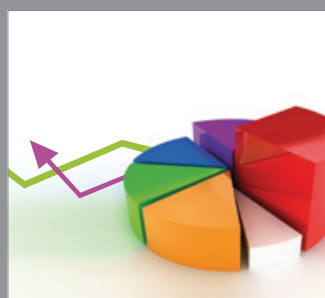

ournal of

Probability and Statistics

Promensencen
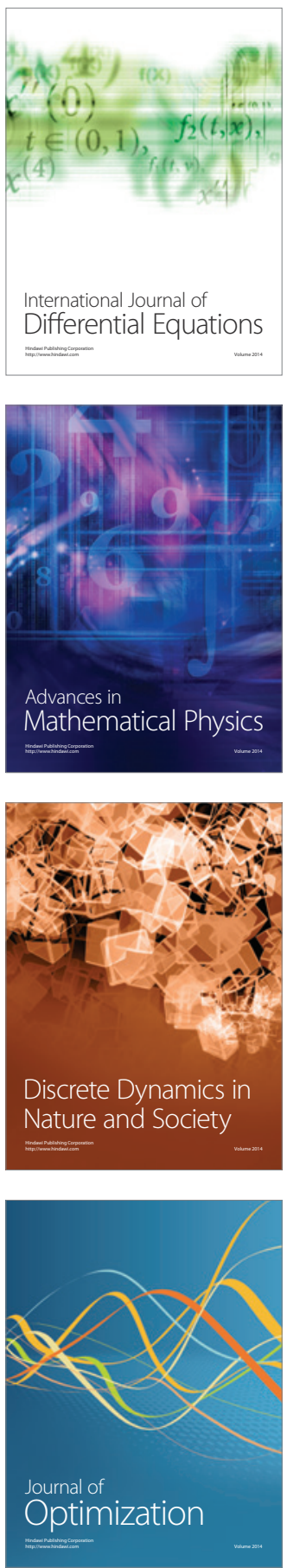